\title{
Notas sobre educação e espaço público em Kant
}

\author{
Sônia Barreto
}

\begin{abstract}
Resumo:
O artigo aborda algumas passagens do projeto pedagógico de Kant, concebendo como horizonte temático o princípio kantiano da destinação humana, destacando alguns passos presentes nas lições Sobre a Pedagogia e seus nexos com sua Filosofia prática, notadamente, com a Filosofia do Direito enquanto instância legitimadora do espaço público.
\end{abstract}

Palavras-chave: Kant; Pedagogia; Direito; Publicidade

\section{Notes about education and space public in Kant}

\begin{abstract}
:
The article discusses some passages of pedagogical designing of Kant as the thematic horizon of principle Kantian of human destination, highlighting some steps in this lesson On Education and its linkages with its practical philosophy, especially with the Philosophy of Law as the legitimacy of public space.
\end{abstract}

Keywords: Kant; Pedagogy; Law; Publicity 
O artigo aborda alguns aspectos da ordenação sistemática da filosofia de Kant, com base no seu projeto pedagógico e sua relação com a filosofia prática, notadamente, com sua Doutrina do Direito. Com esse propósito, tomamos como fio condutor a idéia diretriz do projeto pedagógico de Kant, segundo a qual "Um princípio de pedagogia, o qual mormente os homens que propõe planos para a arte de educar deveriam ter ante os olhos, é: não se deve educar as crianças segundo o presente estado da espécie humana, mas segundo um estado melhor, possível no futuro, isto é, segundo a idéia de humanidade e da sua inteira destinação" (KANT, 1999, p. 22).

Convém notar, primeiramente, que a instauração de um princípio de pedagogia, visando a possibilidade da inteira destinação da humanidade, é norteado por um horizonte temporal futuro, o que permite não somente a abrangência da espécie, mas também comporta a idéia de aperfeiçoamento, o que justifica a possibilidade de aperfeiçoamento da educação. Observemos que esse princípio comparece na pedagogia de Kant em consonância com o desenvolvimento político e, conseqüentemente, é referido ao desenvolvimento efetivo do Estado, uma vez que, ao privilegiar a educação pública, o filósofo a associa ao melhoramento do estado social, enquanto condição de possibilidade da finalidade ética. Nesse horizonte, Kant considera que,

A educação pública tem aqui manifestamente as maiores vantagens: ai se aprende a conhecer a medida das próprias forças e os limites que o direito dos demais nos impõe. Aí não se tem nenhum privilégio, pois que sentimos por toda parte resistência, e nos elevamos acima dos demais unicamente por mérito próprio. Essa educação pública é a melhor imagem do futuro cidadão (KANT, 1999, p. 34, it. nosso).

Assim, podemos considerar que a efetivação de um estado de coexistência das liberdades, tal como é exigido para a instituição do estado jurídico, funda-se no conhecimento dos limites, que nos são impostos pela vontade livre e implica o respeito ao direito do outro, o que assegura a base da indissociável relação entre a finalidade do agir ético, em consonância com a política no pensamento de Kant, uma vez que esta se inscreve na seguinte perspectiva: perseguir a idéia de uma sociedade justa, o que implica o entusiasmo pelo dever moral-jurídico de viver em paz ${ }^{1}$. Na filosofia crítica, a destinação do homem à vida em sociedade comparece como uma disposição pertencente à humanidade ${ }^{2}$.

Nesse sentido, uma vez que Kant considera a educação um projeto em contínuo aperfeiçoamento, o filósofo adverte que não devemos educar as crianças, seguindo o modelo presente do estado em que se encontra a espécie humana; mas considerando, sobretudo, "um estado melhor, possível no futuro". Assim, parece permitido afirmar que, em seu projeto pedagógico, encontram-se presentes, em germe, todos os elementos - desde os mais rudimentares, para a consecução da idéia de comunidade; até a constituição da educação em um projeto que visa à orientação e ao trato dispensado para os outros, enquanto interesse pela humanidade, o que culmina no sentimento cosmopolita.

Visualizando um estado melhor no futuro, a orientação formativa que a educação deve perseguir, põese como condição de possibilidade do progresso social e indica, a partir de princípios, uma preocupação com o aprimoramento das relações e com o espaço compartilhado, não somente visando o atual estado, mas, sobretudo, construindo e estendendo o âmbito das relações políticas, de tal modo que a direção das ações tenha como horizonte o futuro da espécie sob o ponto

\footnotetext{
1 Sobre o tema, ver Loparic, 2003.

2 Cf. CU, §41, p. 161-163, CJ, § 41, p.142-143.
} 
de vista cosmopolita; o que pode ser interpretado, contemporaneamente, como um princípio fundativo da responsabilidade social ${ }^{3}$.

Nas lições Sobre Pedagogia, Kant utiliza uma metáfora que traduz sua idéia de comunidade e de publicidade. Ele diz: "Uma árvore que permanece isolada no meio do campo não cresce direito e expande longos galhos; pelo contrário, aquela que cresce no meio de uma floresta cresce ereta por causa da resistência que lhe opõem as outras árvores, e, assim, busca por cima o ar e o sol" (KANT, 1999, p. 24). Verifica-se que o crescimento é possibilitado pelo conflito, pelas relações de oposição e resistência, ou, conforme Kant, assinala, em Idéia de uma história Universal de um ponto de vista cosmopolita, pela insociável sociabilidade.

Sendo assim, uma condição necessária ao projeto educativo, assinalada por Kant, consiste em perseguir a idéia de um aprimoramento constante e tal finalidade se traduz como parte constitutiva de um projeto político mais amplo, que almeja a idéia de uma organização em comunidade, tendo como finalidade última um estado melhor. É nessa direção que a finalidade da moralidade é a justiça social e esta, por sua vez, implica o reconhecimento de deveres e direitos, obrigações e leis externas ou numa legislação jurídica que possibilite a conciliação entre direito privado e direito público, o que justifica a idéia efetiva de uma comunidade jurídica-política.

Contudo, uma vez que Kant considera a necessidade de uma legislação jurídica, esta implica, por sua vez, uma legislação moral; então se faz necessário ao homem um processo formativo, porque somente pela educação ele pode dar os primeiros passos para a sociabilidade, sendo o primeiro destes a disciplina. Esta, primeiramente "transforma a animalidade em humanidade" (KANT, 1999, p. 12). Considerando assim, vemos que o conceito de hu- manidade, caro à filosofia prática, consiste num estado alcançado somente pela educação, promovido pela disciplina, responsável pela retirada do homem do estado de rudeza em direção à civilidade. Sendo assim, a condição de possibilidade da civilidade e sua exeqüibilidade implicam, originariamente, a implementação de um projeto educativo cosmopolita, fundado em bons princípios, uma vez que o homem "Não é bom nem mau por natureza, porque não é um ser moral por natureza. Torna-se moral apenas quando eleva a sua razão até aos conceitos do dever e da lei" (KANT, 1999, p. 95).

Ora, por não ser nem bom nem mal por natureza, o homem é, originariamente, tanto impulsionado pelos vícios e inclinações, quanto pela razão, que lhe solicita o uso de princípios e leis. Na Crítica $d a R a-$ zão Prática Kant afirma que:

\section{[...] a lei moral, da qual nos tornamos imediatamente conscientes, (tão logo pro- jetamos para nós máximas da vontade), que se oferece primeiramente a nós e que, na medida em que a razão a apresenta como um fundamento determinante sem nenhuma condição sensível preponderan- te, antes, totalmente independente delas, conduz diretamente ao conceito de liber- dade (KANT, KpV, p.53, trad. 2003, p. 101).}

Tal condição peculiar justifica, ao mesmo tempo, a frase com a qual Kant inicia suas lições: "O homem é a única criatura que precisa ser educada" (KANT, 1999, p. 11). Conforme já assinalamos, a educação consiste num processo com base no qual uma geração educa a outra. Nesse sentido, Kant dirá que se há pessoas que se interessam "pelo bem da sociedade e estão aptas para conceber como possível

\footnotetext{
${ }^{3} \mathrm{Na}$ Filosofia contemporânea, o tema da responsabilidade é amplamente debatido por Hans Jonas nas obras Das Prinzip Verantwortung: Versuch einer ethic für die Tecnologische Zivilisation, Insel Verlag, Frankfurt am Main, (Trad. bras. O Princípio Responsabilidade - Ensaio de uma Ética para a Civilização tencológica, de Marijane Lisboa e Luiz Barros Montez, Rio de Janeiro, Editora PUC Rio e Contraponto, 2006) e Das Prinzip Leben: Ansätze zu einer philosophischen Biologie, Insel Verlag, Frankfurt am Main, (Trad. bras. O Princípio vida-Fundamentos para uma biologia filosófica, de Carlos Almeida Pereira, Petrópolis, Editora Vozes, 2004).
} 
um estado de coisas melhor no futuro", então "A direção das escolas deveria, portanto, depender da decisão de pessoas competentes e ilustradas" (KANT, 1999, p. 24). Essa afirmação assinala e confirma a consideração de Kant acerca do modo como se deve gerir as instituições públicas e de que modo os pretendentes aos postos de direção devem alcançá-los: unicamente por mérito próprio. Ora, podemos afirmar que, analisando cuidadosamente as Lições sobre a Pedagogia, lá encontramos todos os requisitos necessários para um projeto que visa atender o pleno desenvolvimento da espécie, que consiste na possibilidade de atingir um estado justo.

Visando perseguir essa idéia, a educação consiste num projeto que implica um conjunto de condições conexas: disciplina, cultura, habilidade, civilidade e, por fim, a moralidade. Esta precede a legalidade, enquanto condição da coexistência das liberdades a qual requer, por sua vez, uma ciência do direito, acerca da qual Kant já adverte na pedagogia, ao tratar da educação prática: "Para educar as crianças na honestidade falta um catecismo do direito em versão popular de casos referentes à conduta que se há de manter na vida cotidiana, e que implicariam naturalmente sempre a mesma pergunta: isso é justo ou injusto?" (KANT, 1999, p. 91, grifo nosso). Essa afirmação de Kant conduz-nos à seguinte consideração: porque somente a educação forma o homem para o exercício da cidadania, o filósofo propõe que, desde cedo, inicie-se uma doutrinação elementar acerca do direito.

Vejamos: que um projeto formativo não esteja desvinculado, também, de um catecismo do direito, tal condição nos permite afirmar que o estatuto da publicidade em Kant tem raízes na educação e por isso, o funcionamento do estado depende da implementação de um projeto pedagógico calcado em princípios éticos. No Conflito das Faculdades lemos que "A ilustração do povo é a sua instrução pública acerca dos seus deveres e direitos no tocante ao Estado a que pertence" (KANT, 1993, p. 106).

Seguindo o horizonte da exposição, percebemos uma relação de co-pertença entre educação e ética. A partir de então, consideremos o grau de complexidade quando se trata da legitimação do exercício da liberdade, uma vez que esta depende da educação e com- porta, por sua vez, a realização do direito público que deve promover a passagem efetiva à práxis da política. Nesse sentido, podemos retomar o princípio de destinação da humanidade como o móbil da pedagogia kantiana, com base no qual se pode inferir, que da efetivação de um projeto pedagógico calcado em princípios, implica a legitimação de um estado justo possibilitado pela sociabilidade, o que demonstra a estreita relação entre a educação e o direito como condutores da publicidade.

Sendo assim, os mecanismos desenvolvidos na esfera pública, têm como finalidade conciliar os interesses individuais, enquanto parte constitutiva de um propósito maior que se refere a toda humanidade. Por isso, vemos que as bases que sustentam o edifício da educação devem promover, no homem, para além da civilidade, o sentimento de respeito, de dignidade, de autonomia que se traduz na moralidade, como parte formativa do caráter. Este terá como norte a distinção relacional e estrutural das bases nas quais se assentam o público e o privado, calcados no direito, que em conexão com a política, possibilita a fórmula positiva da publicidade. Esta, implica na capacidade de fazer uso da razão diante do público, de tornarem públicas as suas idéias através da escrita, de contestar o comportamento da unanimidade artificial, o que garante o princípio transcendental da política. $\operatorname{Em} A$ paz perpétua, Kant afirma que

A verdadeira política não pode, pois, dar um passo sem antes ter rendido preito á moral, e embora a política seja por si mesma uma arte difícil, não constitui no entanto arte alguma a união da mesma com a moral: pois esta corta o nó que aquela não consegue desatar, quando entre ambas surge discrepância (KANT, AK.B, 94-96, trad. p. 106).

\section{II}

Com base no estatuto do projeto pedagógico de Kant e frente à unidade sistemática da sua filosofia, podemos inferir que as reflexões contemporâneas voltadas para a análise, o planejamento, a gestão e a exe- 
cução das políticas públicas não podem prescindir de uma fundamentação filosófica, considerando-se que, em se tratando de um estado jurídico, a legitimidade e efetivação dos princípios fundantes da educação, do direito, da política e do uso do espaço público, implicam a relação positiva entre a educação, o direito e a política, o que pressupõe a aplicação da fórmula do princípio da destinação humana, que se refere ao melhoramento do estado, no sentido de formar cidadãos livres, o que remete à necessidade do conhecimento e da adoção dos princípios, enquanto possibilidade da formação e conservação dos cidadãos, segundo as leis da liberdade ou de acordo com o princípio da autonomia, o que caracteriza uma razão livre ou esclarecida. Acerca do uso prático da razão, Kant afirma que "A razão faz conhecer os princípios [...] não se trata da razão especulativa, mas da reflexão a respeito do que acontece segundo as suas causas e efeitos. Trata-se de uma razão prática em sua economia e em sua disposição" (KANT, 1999, p.70).

Vemos, portanto, que na construção do seu sistema, Kant considera distintamente o domínio fenomênico, no qual se inscrevem os aparecimentos e possibilita sua teoria dos juízos determinantes, do domínio da liberdade, no qual se inscrevem as ações humanas. Esses dois domínios exigem, respectivamente, uma metafísica da natureza e uma metafísica dos costumes. ${ }^{4}$ Assim, Kant elabora propriamente uma arquitetônica, a qual traduz e assegura o seu método, de tal forma que este visa às condições de possibilidade do conhecimento científico, quando se trata dos princípios metafísicos da natureza, bem como do sistema completo da liberdade, no que concerne à metafísica dos costumes. Esta, por sua vez, compreende os aspectos essenciais da atividade humana, a exemplo da educação, da moral, do direito e da política, questões com as quais se ocupa a presente investigação.

Considerando ainda que a unidade sistemática constitutiva do método comporta a copertinência da metafísica da natureza, como fundamentação lógica da dimensão especulativa da razão pura e da metafísica dos costumes, enquanto dimensão prática dessa mesma razão, trataremos, a partir de então, dos princípios norteadores presentes na pedagogia kantiana privilegiando, conforme já assinalamos, a relação da educação com o direito e seu papel determinante no âmbito da publicidade, visando demonstrar que a exeqüibilidade da relação entre o direito e a política, que possibilita a publicidade, está condicionada à educação ${ }^{5}$.

Com base na filosofia prática de Kant e sua delimitação a partir do princípio da liberdade, a pesquisa encontra-se circunscrita no âmbito do domínio de juízos práticos, cuja validade se expressa na fórmula do imperativo categórico a partir da consciência da obrigação moral, que tem como fio condutor o sentimento de respeito. Na Fundamentação da Metafísica dos Costumes, Kant afirma que

\section{[...] embora o respeito seja um sentimen- to, não é um sentimento recebido por in- fluência; é, pelo contrário, um sentimento que se produz por si mesmo através dum conceito da razão, e assim é especificamente distinto de todos os sentimentos do pri- meiro gênero que se podem reportar à in- clinação ou ao medo. [...] respeito que não significa senão a consciência da subordi- nação da minha vontade a uma lei, sem}

\footnotetext{
${ }^{4} \mathrm{O}$ tema é tratado por nós no artigo Do co-pertencimento das duas metafísicas de Kant na implementação do seu projeto pedagógico. Revista do Mestrado em Educação, vol. 10, p. 43-50.

5 Esse percurso, que parte da disciplina à moralidade pela via da destinação humana, inclui sistematicamente elementos presentes nos opúsculos sobre a história, Idéia de uma história universal de um ponto de vista cosmopolita, na Resposta à pergunta: O que é ilumineismo?, no Conflito das Faculdades, na Fundamentação da Metafísica dos Costumes, na Crítica da Razão Prática e em outros opúsculos. No segundo passo, reunimos alguns elementos da Doutrina do Direito do texto Teoria e Práxis e da Antropologia. Cf. Kritik de rpraktischenVernunft, Ueber Paedagogie, Idee zu einer Allgemeinen Geschichte in Weltbürgerlicher Absicht, Grundlegung zur Metaphysik der Sitten, Kritik der reinen Vernunft, Anthropologie in pragmatischer Hinsicht, Metaphysik der Seitte-Rechtslehr. Além dos textos básicos nos apoiamos em outras obras de Kant e de estudiosos da filosofia crítica, conforme consta no referencial bibliográfico.
} 
intervenção de outras influências sobre a minha sensibilidade (KANT, AK, BA16, nota, trad. p.70).

Notamos, assim, que o sentimento de respeito subordina vontade a uma lei, a qual se produz a si mesma necessariamente e, dessa forma, à medida que a liberdade é considerada como fato (Faktum) da razão, esta legitima a condição de possibilidade subjetiva do uso imanente das leis práticas, ou, da facticidade da razão $o^{6}$ do que se infere a sua legitimidade no uso público. A filosofia kantiana não somente nos possibilita uma aproximação com os problemas contemporâneos, mas, à medida que o atual estado político reivindica novos princípios reguladores para as políticas públicas, notadamente no que tange à educação, nossa pesquisa visa relacionar a educação e o conceito positivo de espaço público, uma vez que essa perspectiva permite uma análise profícua acerca da relação de conseqüência entre educação e segurança pública, concebendo a segunda como condição de efetivação de uma proposta pedagógica pautada em princípios éticos, o que promoveria a formação de sujeitos livres, executores de ações pautadas numa razão disciplinada e autônoma, condição indispensável à legitimação do direito público e da efetiva condição de cidadãos livres, partícipes de um estado. Nessa direção, a pedagogia é considerada por Kant como uma "arte raciocinada"; conseqüentemente a formação deverá conduzir à sabedoria do uso da liberdade para que o homem possa viver como um ser livre, o que implica numa razão disciplinada, exigência que precede e possibilita o seu uso público.

$\mathrm{Na}$ Fundamentação da Metafísica dos Costumes, Kant demonstra a necessidade de procurar os fundamentos da moralidade para então, partindo destes, apresentar regras que se estendem para o domínio público. Em sua articulação interna, a investigação conduz à descoberta dos princípios da moralidade e dos modos como esta, exercendo sua influência, atua sobre os arbítrios humanos. Em outro texto, o opús- culo intitulado $O$ que é o esclarecimento? (Was ist Aufklärung?) Kant afirma ser o esclarecimento o passo que permite a saída da menoridade para a autonomia, o que implica a consciência de si como agente moral, movido pelo sentimento de respeito pela lei. Esta, quanto à forma, diferencia-se das leis da natureza, uma vez que a consciência da existência da lei moral deve conduzir à necessidade do respeito a essa mesma lei. Assim, em conexão com a moralidade, o projeto pedagógico de Kant se inscreve no campo da práxis humana e diz respeito a um domínio específico: a liberdade como base de todas as ações, a partir da qual o homem deve unicamente agir.

Assim posto, o respeito possibilita a recepção da lei moral e esta receptividade consiste no modo como a lei se torna acessível para a pessoa. Se, por um lado, esse sentimento não "fundamenta" a lei; por outro, ele consiste no modo de manifestação da lei. Isso implica dizer que a submissão à lei, não implica o afastamento daquilo que eu mesmo sou, porque, sujeitando-me à lei, eu me sujeito a mim mesmo como razão pura, o que permite que eu me determine como ente livre e digno de respeito.

\section{III}

Podemos afirmar que a possibilidade de determinação para o agir livre está conectada ao conceito de educação, que, na filosofia de Kant, é pensado de tal forma que o processo pedagógico deve servir como ponto de partida para a realização da destinação humana, uma vez que o homem formado que passou por todas as etapas da educação, tornar-se-ia um homem esclarecido. Assim, se o processo pedagógico consiste na formação do homem, desde a aquisição de conhecimentos, até o mais alto grau de esclarecimento, este implica conseqüentemente a sua saída da menoridade e a ousadia de aprender a pensar por si próprio, o que culmina no ideal do uso público da razão, possibilidade da qual depende o conhecimento de direitos e deveres.

\footnotetext{
${ }^{6}$ Cf. Loparic, 2003.
} 
Na Introdução da obra Sobre a Pedagogia, são expostas as fases do desenvolvimento formativo, assim como os obstáculos que impedem a realização plena desta idéia. Seguindo a direção esboçada por Kant, a educação se divide em duas fases: o Cuidado ou a Educação Física e a Formação ou a Educação Prática/Moral. Na primeira, o constrangimento é mecânico, modo pelo qual as crianças aprendem diversas artes para sua vida presente; na segunda, o constrangimento é moral, fase na qual se deve desenvolver a natureza humana de forma que as projeções visem o melhoramento das gerações futuras, o que demonstra a dinamicidade de tal projeto, a possibilidade de ser retomado, revisado e ampliado, além do fato da dimensão de um melhoramento do estado social, com base na idéia da construção futura de em estado melhor, pelo aprimoramento dos projetos pedagógicos.

Considerando, portanto, que a formação se divide em disciplina e cultura, primeiro a criança deve ser disciplinada, a fim de aprender a dominar ou moldar seus instintos e pautar-se por ações raciocinadas e não por impulso; o papel da disciplina consiste no auxílio que esta presta, quando se trata da submissão civilizada às leis da humanidade, o que se põe como condição de possibilidade da sociabilidade e da efetivação da publicidade, enquanto condição do convívio na esfera pública. Nesse sentido podemos entender a importância do caráter negativo da disciplina. De acordo com Kant

\section{[...] as crianças são mandadas à escola não} para que aí aprendam alguma coisa, mas para que ai se acostumem a ficar sentadas tranqüilamente e a obedecer pontualmente aquilo que lhes é mandado, a fim de que no futuro não sigam de fato e imediatamente a cada um de seus caprichos. Mas o homem é tão naturalmente inclinado à liberdade que, depois que se acostuma a ela por longo tempo, a ela tudo sacrifica. Ora, esse é o motivo preciso, pelo qual é conveniente recorrer cedo à disciplina; pois, de outro modo, seria muito difícil mudar depois o homem (KANT, AK, 442, trad. p.13).
Relacionando, pois, a disciplina à cultura, esta última torna o homem "prudente", uma vez que, conhecendo o seu lugar na sociedade, ele pode agir com polidez e modos corteses e gentis. Assim, a cultura e a instrução são as condições prévias necessárias ao desenvolvimento da capacidade do homem de escolher, entre os fins, apenas aqueles que se destinam à perfeição da humanidade, o que constitui um passo importante no processo de moralização. Acerca da diferença entre a civilidade e a moralidade, Höffe faz a seguinte observação: "Instruído por Rousseau, Kant não infere do refinamento do gosto uma correspondente elevação do sentimento moral; a civilização não significa já moralização; o desenvolvimento do sentido comum tem só significado estético, e não também significado moral" (HÖFFE, 2005, p. 304).

Mas, conforme assinalamos, Kant estabelece a diferença entre a educação pública e a educação privada, mostrando as vantagens que o estado teria se investisse na formação pública, considerando-se que esta seria ministrada por instituições de ensino que em tese deveriam depender da decisão "de pessoas competentes e ilustradas”. Tal afirmação está em perfeita conexão com o projeto pedagógico de Kant, uma vez que o filósofo adota como princípio a realização do pleno desenvolvimento da destinação humana, o que implica outro requisito para o seu cumprimento: "Uma educação pública completa é aquela que reúne, ao mesmo tempo, a instrução e a formação moral" (KANT, AK. p.452, trad. p.30).

De tal modo, a indissociável relação entre educação e moralidade, no âmbito público, visa à dignidade humana, com base na qual todos os homens estariam, ao mesmo tempo, sujeitos à lei moral, o que representa o primeiro passo na efetivação das leis externas, notadamente do direito público, que garante a sociabilidade a qual somente se exerce plenamente na esfera do espaço público. Visando tais realizações, Kant reconhece que um projeto de educação é sempre apenas um esboço.

Ora, se Kant reivindica o aperfeiçoamento de cada geração, então cada uma deve ampliar, pela via da educação, o seu grau de eficácia e, sendo a arte de educar uma "arte raciocinada", ela não pode ser concebida apenas de forma mecânica, visando à utilida- 
de presente, mas deve ser pensada de tal forma que apresente como fio condutor uma proposta que vise ao melhoramento das futuras gerações que em Kant se traduz em termos morais.

Contudo, lamenta Kant, parece que os governantes são sempre desfavoráveis à educação, porque os príncipes ou governantes, quando se envolvem em guerras, gastam com isso todos os recursos financeiros dos Estados, esquecendo-se das instituições de ensino, e, conseqüentemente do aperfeiçoamento da humanidade ${ }^{7}$. Ora, se todos os problemas relacionados à educação são reproduzidos no estado, por sua vez, o melhoramento do estado social é um objetivo a ser atingido somente pela educação.

Nessa direção, Kant aponta duas possibilidades: uma estaria ligada ao empenho do povo em aperfeiçoar-se e não somente esperar a ajuda dos governos; e quanto aos governos, empenharem-se em melhorar a educação, tirando-a dos graves erros a que está inserida. Tais procedimentos implicariam na adoção do seguinte princípio: os homens devem se empenhar, com o objetivo de sempre ultrapassar, de fazer mais e melhor, no que tange ao acúmulo de conhecimentos herdados de uma geração anterior. Tal princípio se liga à idéia de progresso da humanidade, uma vez que uma época civilizada, não implica que seja, exatamente por isso, moralizada.

Ainda quanto ao co-pertencimento entre educação e moralidade, que tem implicações diretas com as relações públicas, Kant considera que, ao elaborarmos um projeto pedagógico, faz-se necessário ainda sabermos se em sua aplicação ele dará certo. Para isso, é necessário detectarmos seus pontos falhos a fim de tentarmos inserir as modificações, o que requer que se observe primeiro a sua aplicação na prática, de modo que a experiência nos diga onde, como e porque melhorar; tal procedimento implica, portanto a implementação de escolas experimentais:
Crê-se geralmente que não é preciso fazer experiência em assuntos educacionais $e$ que se pode julgar unicamente com a razão se uma coisa será boa ou má. Quanto a isso erra-se muito e a experiência ensina que as nossas tentativas produziram de fato resultados opostos àqueles que esperávamos. Vê-se, pois, que sendo nesse assunto necessária a experiência, nenhuma geração pode criar um modelo completo de educação (KANT, AK. p.451, trad. p. 29).

Podemos afirmar que, entre os importantes elementos que podem ser retomados da pedagogia kantiana, um constitui, especificamente, um elemento propulsor para a retomada de Kant na atualidade: o fato de seu projeto pedagógico ser motivado pela preocupação com o melhoramento, com o aperfeiçoamento do seu modelo didático e moral, o que implica a responsabilidade política de cada geração para com as gerações futuras.

Nessa direção, se a educação é pensada como formação, ela contribui para a legitimação da práxis política, enquanto é condição do aperfeiçoamento das relações públicas, porque o princípio da publicidade possibilita a passagem da teoria do direito à práxis da política, tendo em vista os interesses do povo e suas exigências morais: aqui destacamos um nexo possível entre a educação e a segurança pública.

Nesse sentido, podemos dizer que a plausibilidade da relação entre a educação e o conceito positivo de espaço público se fundamenta numa proposta pedagógica pautada em princípios éticos, o que promoveria a formação de sujeitos livres, condição indispensável para o efetivo exercício da publicidade, uma vez que, para Kant, na moral, tudo o que é correto para a teoria deve também valer para a prática.

7 Cf. Idee zu einer Allgemeinen Geschichte in Weltbürgerlicher Absicht, (oitava proposição) 


\section{Referências}

Werkausgabe. Die Werke Immanuel Kant in der Ausgabe von Wilhelm Weischedel, Suhrkamp Tachenbüchern Wissenschsft in zwölf Bände, Frankfurt, 1968.

ALLISON, Henry E. Kant's Transcendental Idealism. An Interpretation and Defense. N. Haven: Yale University Press, 1983, Trad. cast: El Idealismo transcendental de Kant, de Dulce Maria G.Castro, Barcelona: Anthropos, 1992.

ARENDT, Hannah. Lições sobre a filosofia política de Kant. Trad. port. de André Duarte de Macedo, Rio de Janeiro: Relume-Dumará, 1993.

BARRETO, Sônia. "A determinação fundamental do tempo na teoria kantiana do juízo". In: Philosophica - Revista de Filosofia da História e Modernidade, número 4, São Cristovão: 2003, p. 57-73.

"Do co-pertencimento das duas metafísicas de Kant na implementação do seu projeto pedagógico". In: Revista do Mestrado em Educação, v. 10, jan a jun. São Cristovão: 2005, p. 43-50.

"Da semântica Transcendental à semântica Existencial: Kant e Heidegger". In: PhilosophicaRevista de Filosofia da História e Modernidade, número 7, São Cristovão: 2006, p. 93-110.

. "Esquematismo transcendental e ontologia fundamental: Heidegger intérprete de Kant". In: SANTOS, Antonio Carlos (Org.). História, Pensamento e Ação, São Cristóvão: Editora UFS, 2006, p. 321334

"O esquematismo Transcendental: da sensibilização dos conceitos à semântica transcendental”. In: SALLES, João Carlos (Org.).
Pesquisa e Filosofia-Coleção Ensaios de Filosofia Contemporânea. Salvador: Editora Quarteto, 2007, p. 333-358.

BOBBIO, Norberto. Direito e Estado no pensamento de Emanuel Kant. Trad. Bras. de Alfredo Fait, 2 ed, Brasília: Ed. Universidade de Brasília, 1992.

Estado Governo Sociedade - para uma teoria geral da política. Trad. Bras. de Marco Aurélio Nogueira, Rio de Janeiro: Ed. Paz e Terra, 1987.

CAYGILL, Howard. A Kant Dictionary, Blackwell Publishers de Oxford, Inglaterra. Trad. bras. Dicionário Kant, de Álvaro Cabral, Rio de Janeiro: Zahar, 2000.

CASSIRER, Ernst. An Essay on Man. New Haven, Connecticut, U.S.A. Trad. bras. Antropologia Filosófica-ensaio sobre o homem, de Vicente Felix de Queiroz, São Paulo: Editora Mestre Jou, 1977.

Die Philosophie der Aufklärung, Trad. port. A filosofia do Iluminismo, de Álvaro Cabral. Campinas: Ed. da UNICAMP, 1994.

CASNABET, Michèle Crampe. Kant Une revolution philosophique, Paris, Editions Bordas, Trad. bras. Kant-uma revolução filosófica, de Lucy Magalhães, Rio de Janeiro: Jorge Zahar Editor, 1994.

CHÂTELET, François. Une Historie de la Rason (entretiens avec Émile Noel), Paris, Editions du Seuil, Trad. bras. Uma história da Razão, de Lucy Magalhães, Rio de Janeiro: Jorge Zahar Editor, 1994.

EISLER, R. Kant-Lexikon. Hildesheim: Olms, 1964.

HEIDEGGER, Martin. Kant und das Problem der Metaphysik Trad. cast. , Kant y el problema de la 
metafísica. de Gred Ibscher Roth, México: Fondo de Cultura Económica, 1986.

. Kants These über das Sein. Trad. bras. A tese de Kant sobre e ser de Ernildo Stein, São Paulo: Duas Cidades, 1970.

Die Frage nach dem Ding. Trad. port. Que é uma Coisa? de Carlos Morujão, Lisboa: Edições 70, 1992.

HERRERO, Francisco Xavier. Religión e historia en Kant. Trad. port. Religião e História em Kant. de José A. Ceschia, São Paulo: Loyola, 1991.

HÖFFE, O. Immanuel Kant. Trad. Bras. Immanuel Kant. de Christian V. Hamm e Valério Rohden, São Paulo: Martins Fontes, 2005.

O que é justiça? Trad. Bras. de Peter Naumann, Porto Alegre: EDIPUCRS, 2003.

KANT, Immanuel. Kritik der reinen Vernunft. Trad. port.: Crítica da Razão Pura. de Manuela Pinto dos Santos e Alexandre Fradique Morujão, Lisboa: Fundação Calouste Gulbenkian, 1994.

Kritik der pratischen Vernunft. Trad. port.: Crítica da razão prática. de Artur Morão, Lisboa: Edições 70, 1989.

. Grundlegung zur Metaphysik der Sitten. Trad. port.: Fundamentação da Metafísica dos Costume, de Paulo Quintela, Lisboa,: Edições 70, 1986.

Prolegomena zu einer jeden künftigen Metaphysik die als Wissenschaften wirde auftreten könenen. Trad. port. Prolegómenos a toda a metafísica Futura, de Artur Morão. Lisboa: Edições 70, 1987.

Idee zu einer Allgemeinen Geschichte in Weltbürgerlicher Absicht. Trad. port.: Idéia de uma história universal de um ponto de vista cosmopolita. de Rodrigo Naves e Ricardo R. Terra, São Paulo: Brasiliense, 1986.
Teoria y Práctica. Trad. de Juan Palácios, M. Francisco López e Roberto R. Aramayo. Madrid: Tecnos, 1986.

Anthropologie in pragmatischer Hinsicht. Trad.port. Antropologia de um ponto de vista Pragmático. de Célia Aparecida Martins, São Paulo: Iluminuras, 2006.

Metaphysik der Seitten. "Rechtslehre". Trad. port. Doutrina do Direito, de Edson Bini, São Paulo: Editora Ícone, 1993.

Ueber Paedagogie. Trad. bras. Sobre a pedagogia. de Francisco Cock Fontanella, São Paulo: editora UNIMEP, 1999.

Was heisst: sich im Denken orientieren? Trad. br.: Que significa orientar-se no pensamento? de Floriano de Sousa Fernandes, Petrópolis: Vozes, 1985.

Carta a Marcus Herz. Trad. port. de Antonio Marques, Lisboa: Imprensa Nacional Casa da Moeda, 1985.

LEBRUN, Gerard. Kant et la fin de la métaphysique. Trad. br.: Kant e o fim da metafísica. de Carlos Alberto R. de Moura, São Paulo: Martins Fontes, 1993.

LONGUENESSE, B. Kant et le pouvoir de juger. Sensibilité et discoursivité dans L'analytique transcendentale de la Critique de la rason pure. Paris: PUF, 1993.

LOPARIC, Zeljko. Heurística kantiana, Cadernos de História e Filosofia da Ciência. n.5, 1983, pp. 73-89, 1983

"O Fato da Razão -Uma interpretação

Semântica”. Analytica, vol. IV, n.1.

A Semântica Transcendental de Kant. Campinas: Col. CLE, 2000.

"O problema fundamental da semântica jurídica de Kant”. In: SMITH, P.WRIGLEY, M. 
(Orgs.) O filósofo e sua história. Campinas: Unicap/ CLE, pp.481-524, 2003.

MARIA DE LURDES BORGES e JOSÉ HECK (orgs.) Kant; liberdade e natureza. Florianópolis: Ed. da UFSC, 2005.

MENEZES, Edmilson . História e Esperança em Kant. São Cristóvão: Ed. Univ. Federal de Sergipe: 2000.

NOUR, Soraya . À paz perpétua de Kant. São Paulo: Martins Fontes, 2004

PHILONENKO, A. L'oeuvre de Kant. La philosophie critique. Tome I Paris: J. Vrin, 1997.
ROHDEN, Valério (org.) Kante a Instituição da Paz. Porto Alegre: Ed. da UFRGS, Goethe-Institut/ICBA, 1997.

TERRA, Ricardo Ribeiro. "Algumas questões sobre a filosofia da história em Kant”. In: Idéia de uma história universal de um ponto de vista cosmopolita. São Paulo: Brasiliense, pp.43-73, 1986.

"A arquitetônica da filosofia prática de Kant”. Studia kantiana, v. 1,n.1,1998, pp. 291-306, 1998

Passagens - Estudos sobre a filosofia de Kant. Rio de Janeiro:Editora da UFRJ, 2003.

ZINGANO, M.A. Razão e História em Kant. São Paulo: Editora Brasiliense, 1989.

\section{Sobre a autora}

Sônia Barreto Freire é doutora em Filosofia pela UNICAMP. Professora de Filosofia no Departamento de Filosofia da Universidade Federal de Sergipe. Atua nas áreas de Filosofia Moderna e Contemporânea. É membro pesquisador do NEPHEM e coordena o Grupo de Estudos Kant - NEPHEM. É membro da Sociedade Kant brasileira, do Grupo Criticismo e Semântica - UNICAMP e da Sociedade Brasileira de Fenomenologia. 
